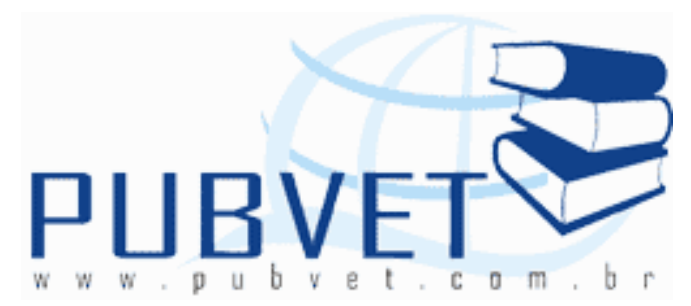

PUBVET, Publicações em Medicina Veterinária e Zootecnia.

\title{
A incidência do vírus rábico transmitido por quirópteros nas regiões do Alto Araguaia e Sudoeste de Goiás
}

\section{Luiz Antonio Silva ${ }^{1}$ e Silvia Rosana Pagliarini Cabral²}

${ }^{1}$ Acadêmico do curso de Ciências Biológicas Licenciatura e Bacharelado. Universidade de Rio Verde - FESURV.

${ }^{2}$ Professora Mestre adjunta da Universidade de Rio Verde - FESURV do Curso Ciências Biológicas Licenciatura e Bacharelado.

\section{Resumo}

O presente estudo reporta a incidência do vírus rábico em bovinos, equinos e quirópteros nas regiões do Alto Araguaia e Sudoeste de Goiás, no período de 2000 a 2010. Os dados foram obtidos do arquivo da Agencia Goiana de Defesa Agropecuária (AGRODEFESA) do Laboratório de Análises e Diagnóstico Veterinário (LABVET) totalizando em 502 amostras. As amostras do sistema nervoso central destes animais foram submetidas à técnica de imunofluorescência direta e inoculação em camundongos. Constatou-se positividade ao vírus em 111 amostras de bovinos, 8 em equinos e nenhum relato para quirópteros. A região do Sudoeste apresentou o maior número de casos positivos ao vírus. A maioria dos morcegos analisados foi da espécie Desmodus rotundus. Sugere-se, um estudo completo sobre os aspectos biológicos dos quirópteros encaminhados para análise e também uma maior 
intensificação no número de amostras enviadas, o que contribuirá para o conhecimento destes animais na epidemiologia da raiva.

Palavras-chave: Morcegos hematófagos, morcegos não hematófagos, vírus da raiva, zoonose, epidemiologia.

\title{
The incidence of rabies virus transmitted by chiropterans in the regions of High Araguaia and South West of Goiás
}

\begin{abstract}
This study reports the incidence of rabies virus in cattle, horses and bats in the High Araguaia and South west of Goiás, in the period 2000 to 2010. The data were obtained from the files of Goiana Agriculture Defense Agency Laboratory of the Veterinary Diagnosis and Analysis (LABVET), totaling in 502 samples. Samples of the central nervous system of these animals were subjected to direct immunofluorescence and mouse inoculation. It was found positive to the virus in 111 samples of cattle, 8 in horses and no account to Chiropterans. The South West registered the highest number of positive cases for the virus. Most bat species was analyzed Desmodus rotundus. It's suggested, a intensive and complete study of the biological aspects of bats sent for analysis and also, a further escalation in the number of samples sent, which will contribute to the knowledge of these animals in the epidemiology of rabies.
\end{abstract}

Keywords: hematophagous bats, non-vampire bats, rabies, zoonosis, epidemiology. 
SILVA, L.A. e CABRAL, S.R.P. A incidência do vírus rábico transmitido por quirópteros nas regiões do Alto Araguaia e Sudoeste de Goiás. PUBVET, Londrina, V. 6, N. 22, Ed. 209, Art. 1396, 2012.

\section{INTRODUÇÃO}

O grupo dos quirópteros é um dos mais diversificados dentre os mamíferos, com 18 famílias, 202 gêneros, e 1120 espécies (SIMMONS, 2005), representando aproximadamente $22 \%$ das espécies de mamíferos catalogados (WILSON \& REEDER, 2005), onde 167 espécies são encontradas no Brasil (REIS et al., 2006). Estes animais têm grande importância médica sanitária, por serem hoje um dos principais portadores do vírus rábico (CUNHA et al., 2006), tendo em vista que no ano de 2010 duas pessoas morreram pelo vírus da raiva, sendo uma transmitida por morcego e outra por cão (BRASIL, 2010).

A raiva é considerada uma doença endêmica, com distribuição epidemiológica bastante heterogênica, e está diretamente relacionada com as condições socioeconômicas e culturais dos estados, sendo a região CentroOeste um local de incidência relevante (LAZARINI, 2003), além disso, esta doença tem afetado grande parte do mundo (SOUZA et al., 2005).

A doença é uma enfermidade infecciosa aguda que atinge o sistema nervoso central (SNC) e pode ser transmitida pela inoculação do vírus por mordedura, lambedura e arranhadura; onde o infectado pode apresentar diversos sintomas como: fobias, paralisia, síndromes entre outros (KOTAIT at al., 2009), sendo as fezes, urina e saliva destes animais o fator principal pela disseminação do vírus (CARNEIRO et al., 2009). Portanto a doença possui grande importância epidemiológica, tendo esta zoonose provocado um impacto expressivo para a saúde pública e animal, devido sua alta letalidade (WARRELL \& WARRELL, 2004), resultando na morte tanto de animais como de seres humanos (OMS, 2005).

O Vírus da raiva pertence à família Rhabdoviridae, gênero Lyssavirus (SILVA \& LANGONI, 2011), sendo classificado em onze espécies e sete genótipos (I, II, III, IV, V, VI e VII), sendo as espécies: Rabies virus (RABV), Duvenhage virus (DUVV), European bat Lyssavirus type 1 (EBLV1), European bat Lyssavirus type 2 (EBLV2), Australian bat Lyssavirus (ABLV), Lagos bat Lyssavirus (LBV), Mokola virus (MOKV), Aravan virus (ARAV), Khujand virus 
SILVA, L.A. e CABRAL, S.R.P. A incidência do vírus rábico transmitido por quirópteros nas regiões do Alto Araguaia e Sudoeste de Goiás. PUBVET, Londrina, V. 6, N. 22, Ed. 209, Art. 1396, 2012.

(KHUV), Irkut virus (IRKV), West Caucasian bat virus (WEBV). As onze espécies descritas do vírus, 10 são encontradas em morcegos, não se encontrando em morcegos a espécie Mokola virus (KOTAIT et al., 2009).

Na América Latina, o principal hospedeiro do vírus rábico dentre os quirópteros são os da espécie Desmodus rotundos classificados como hematófagos, sendo considerados o principal transmissor da raiva em bovinos, herbívoros e inclusive em humanos (SCHNEIDER et al., 2009). O contato direto com esses morcegos pode oferecer grandes riscos em populações animais e humanos (SILVA et al., 2007). Outras duas espécies de morcegos hematófagos Diphylla ecaudata e Diaemus youngi possuem como principal dieta alimentar o sangue de aves, entretanto, pode haver casos de se alimentarem de humanos, podendo, desta forma transmitirem o vírus rábico, porém sua participação nos ciclos de infecção é irrelevante(BATISTA et al., 2007).

Os morcegos não hematófagos tem se tornado portadores do vírus da raiva com mais frequência nos últimos anos, o qual inclui espécies de insetívoros, frugívoros, omnívoros, polinívoros e piscívoros (SCHEFFER et al., 2007). São contaminados pelos morcegos hematófagos devido às diferentes interações, como disputas por território. Esses animais tem se refugiado para as áreas urbanas, por intervenção desordena e inadequada do homem em seu ecossistema natural, o que fortalece a disseminação da doença entre as diferentes espécies (CARNEIRO et al., 2009).

Na América Latina os hematófagos são responsáveis por grandes perdas na pecuária (ACHA \& SYFRES, 2003), onde se estima que a prevalência de bovinos sob risco da doença seja aproximadamente de 70 Milhões de cabeças, com óbitos de aproximadamente até 500.000 animais por ano (BARROS et al., 2006) e no Brasil aproximadamente 30.000 cabeças de gado morrem anualmente por causa da contaminação do vírus (SILVA et al., 2000), sendo um dos maiores problemas econômicos em todos os estados brasileiros (LEMOS \& CAVALLÉRO, 2001). Vale também ressaltar que Rio Verde-Go é hoje um dos municípios brasileiros que possui um dos principais pólos na produção 
agropecuária, onde se destaca especialmente a produção de bovinos de corte e leiteiros (SILVA, 2004), portanto se torna importante um maior controle da veiculação e disseminação do vírus rábico nas regiões próximas.

O presente trabalho tem como objetivo realizar o levantamento da incidência do vírus rábico transmitido por quirópteros nas regiões do Alto Araguaia e Sudoeste de Goiás, e ainda comparar as diferentes regiões quanto à prevalência da doença, incidência de mortes causadas pelos vírus rábico em equinos e bovinos, quantificando o número de morcegos capturados para análises.

\section{METODOLOGIA}

As informações foram obtidas do arquivo da Agencia Goiana de Defesa Agropecuária (AGRODEFESA) do Laboratório de Análises e Diagnóstico Veterinário (LABVET), de acordo com as regiões referentes às sedes estabelecidas pela AGRODEFESA, durante o período de 2000 a 2010. Foram coletadas 502 amostras do sistema nervoso central dos quirópteros, bovino e equino, provenientes do Alto Araguaia (Aparecida do Rio Doce, Aporé, Caçu, Chapadão do Céu, Diorama, Itajá, Itarumã, Ivolândia, Jatai, Lagoa Santa, Mineiros, Perolândia, Portelândia, Santa Isabel, Santa Rita do Araguaia e Serranópolis,) e Sudoeste de Goiás (Acreúna, Aurilândia, Cachoeira Alta, Cachoeira de Goiás, Castelândia, Firminópolis, Gouverlândia, Indiara, Jandaia, Maurilândia, Montividiu, Palminópolis, Paranaiguara, Paraúna, Quirinópolis, Rio Verde, Santa Helena de Goiás, Santo Antonio da Barra, São João da Paraúna, São Luis dos Montes Belos, São Simão, Turvânia, Turvelândia e Vicentinópolis), assim distribuídas: 345 amostras foram de bovinos, 21 amostras de equinos, 100 amostras de morcegos hematófagos e 36 amostras de morcegos não hematófagos.

A técnica de imunofluorescência Direta (IFD) foi empregada de acordo descrita por Kaplan et al. (1996), onde se baseia no exame de amostras de cérebros, hipocampo e córtex de animais com a suspeita de estarem 
SILVA, L.A. e CABRAL, S.R.P. A incidência do vírus rábico transmitido por quirópteros nas regiões do Alto Araguaia e Sudoeste de Goiás. PUBVET, Londrina, V. 6, N. 22, Ed. 209, Art. 1396, 2012.

contaminados com o vírus da raiva, através de um conjugado de anticorpos identificados com a substância fluorescente (isotiocianato de fluoresceína).

A técnica de prova biológica (inoculação em camundongo) onde foi realizada de acordo com Kaplan et al. (1996), trata-se de uma suspensão de $0,3 \mathrm{ml}$ de amostras do cérebro de morcegos, bovinos e eqüinos; onde é processada e inoculada intracerebralmente em camundongos recém desmamados, e depois se observa por 30 dias o animal, caso apresente qualquer sintomatologia da doença, o mesmo é submetidos ao teste de IFD.

\section{RESULTADOS E DISCUSSÃO}

Das 502 amostras submetidas às analises antigênica dos vírus da raiva, os resultados demonstraram que dentre elas $76,29 \%$ foram negativas e $23,71 \%$ positivas.

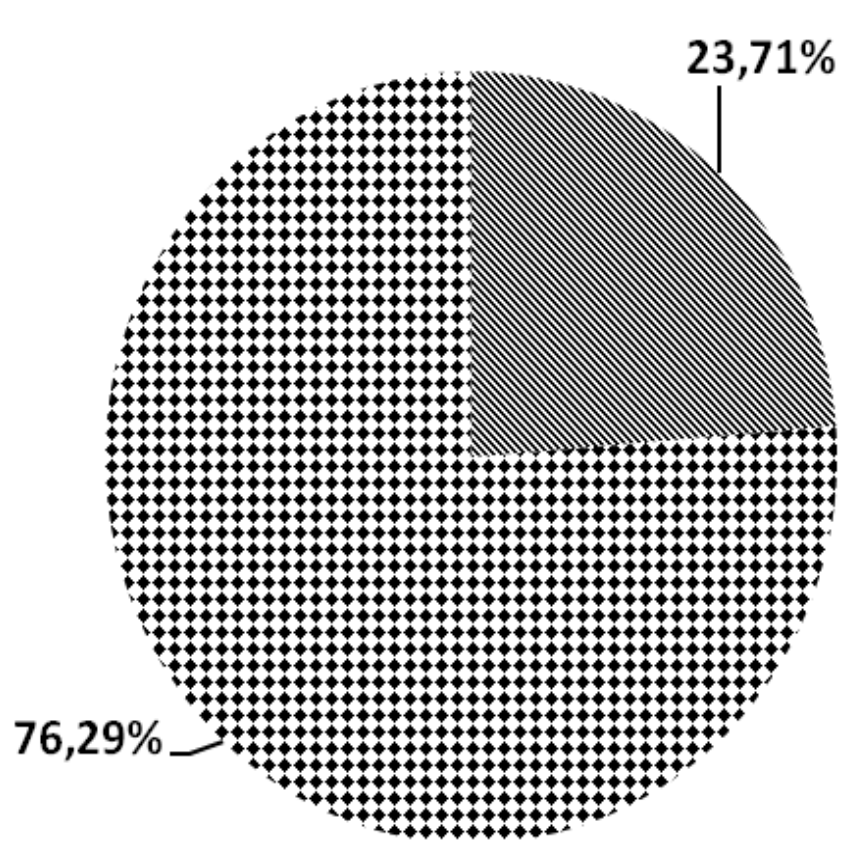

N Positivas

Negativas

FIGURA 1. Porcentagem de amostras positivas e negativas ao vírus da raiva em bovinos, equinos e quirópteros encaminhados ao Laboratório de Análises e Diagnóstico Veterinário (LABVET) de Goiânia, no período de 2000 a 2010 nas regiões do Sudoeste e Alto Araguaia do Estado de Goiás. 

regiões do Alto Araguaia e Sudoeste de Goiás. PUBVET, Londrina, V. 6, N. 22, Ed. 209, Art. 1396, 2012.

Entre as amostras de bovinos $111(32,17 \%)$ deram resultados positivos e $234(67,83 \%)$ negativos. Nas amostras de equinos 8 (38,1\%) foram positivas e 13 (61,9\%) negativas. Entre os morcegos hematófagos 100\% apresentaram resultados negativos, o mesmo se observou para os morcegos não hematófagos. Portanto neste período não foi registrado nenhum caso de morcegos contaminados pelo vírus rábico. Comparando as duas regiões, verifica-se a quantidade de morcegos examinados provenientes da região do Alto Araguaia é significativamente maior que a da região Sudoeste (Figura 2), isso mostra que existe um maior monitoramento de coletas nesta região.

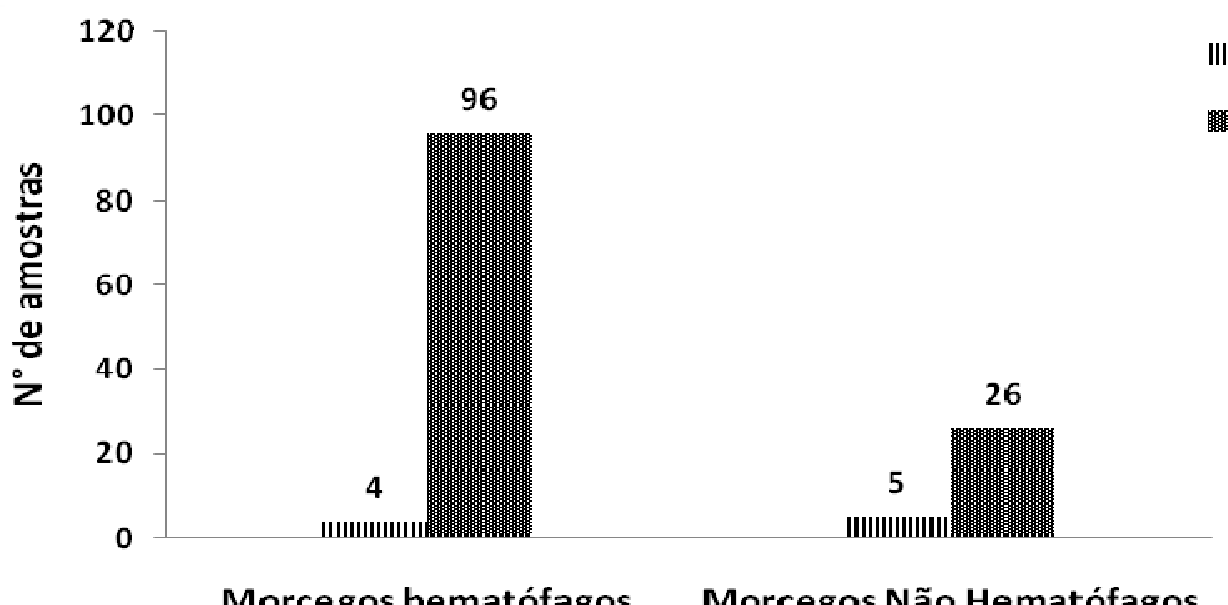

IIII Sudoeste

Auto Araguaia

FIGURA 2. Distribuição dos morcegos hematófagos e não-hematófagos capturados e examinados no Laboratório de Análises e diagnóstico Veterinário (LABVET) de Goiânia, no período de 2000 a 2010 nas regiões do Sudoeste e Alto Araguaia do Estado de Goiás.

Nos municípios da região do Alto Araguaia, a incidência de bovinos contaminados com o vírus rábico foi de 43 positivas e 97 negativas, sendo município de Jataí o que apresentou a maior incidência de bovinos contaminados totalizando em 18 amostras, seguido por Mineiros com 11 amostras (Tabela 1). 
SILVA, L.A. e CABRAL, S.R.P. A incidência do vírus rábico transmitido por quirópteros nas regiões do Alto Araguaia e Sudoeste de Goiás. PUBVET, Londrina, V. 6, N. 22, Ed. 209, Art. 1396, 2012.

TABELA 1. Resultados das amostras positivas (Pos.) e negativas (Neg.) da Região do Alto Araguaia de Goiás para o vírus da raiva, pela técnica de imunofluorescência direta e inoculação em camundongos, realizado no Laboratório de Análises e diagnóstico Veterinário (LABVET) de Goiânia em bovinos, equinos, morcegos hematófagos (MH) e morcegos não hematófagos (MNH), no período de 2000 a 2010.

\begin{tabular}{lcccccccccc}
\hline \multirow{2}{*}{ Municípios } & \multicolumn{3}{c}{ Bovinos } & \multicolumn{3}{c}{ Equinos } & \multicolumn{3}{c}{ MH } & \multicolumn{2}{c}{ MNH } & \multirow{2}{*}{ Total } \\
\cline { 2 - 8 } & Pos. & Neg. & Pos. & Neg. & Pos. & Neg. & Pos. & Neg. & \\
Aparecida do Rio Doce & 0 & 1 & 0 & 0 & 0 & 0 & 0 & 0 & 1 \\
Aporé & 1 & 8 & 0 & 0 & 0 & 53 & 0 & 0 & 62 \\
Caçu & 0 & 10 & 0 & 0 & 0 & 23 & 0 & 1 & 34 \\
Chapadão do Céu & 0 & 0 & 0 & 0 & 0 & 0 & 0 & 0 & 0 \\
Diorama & 0 & 1 & 0 & 0 & 0 & 0 & 0 & 0 & 1 \\
Itajá & 0 & 7 & 0 & 0 & 0 & 0 & 0 & 0 & 7 \\
Itarumã & 6 & 4 & 0 & 0 & 0 & 4 & 0 & 0 & 14 \\
Ivolândia & 1 & 0 & 0 & 0 & 0 & 0 & 0 & 0 & 1 \\
Jataí & 18 & 34 & 0 & 2 & 0 & 4 & 0 & 25 & 83 \\
Lagoa Santa & 0 & 0 & 0 & 0 & 0 & 0 & 0 & 2 & 2 \\
Mineiros & 11 & 17 & 0 & 0 & 0 & 0 & 0 & 0 & 28 \\
Perolândia & 1 & 0 & 0 & 0 & 0 & 2 & 0 & 0 & 3 \\
Portelândia & 1 & 6 & 0 & 0 & 0 & 0 & 0 & 0 & 7 \\
Santa Izabel & 0 & 0 & 0 & 0 & 0 & 0 & 0 & 0 & 0 \\
Santa Rita do Araguaia & 1 & 2 & 0 & 0 & 0 & 0 & 0 & 0 & 3 \\
Serranópolis & 3 & 7 & 0 & 0 & 0 & 10 & 0 & 2 & 22 \\
\hline Total & 43 & 97 & 0 & 2 & 0 & 96 & 0 & 30 & 268 \\
\hline
\end{tabular}

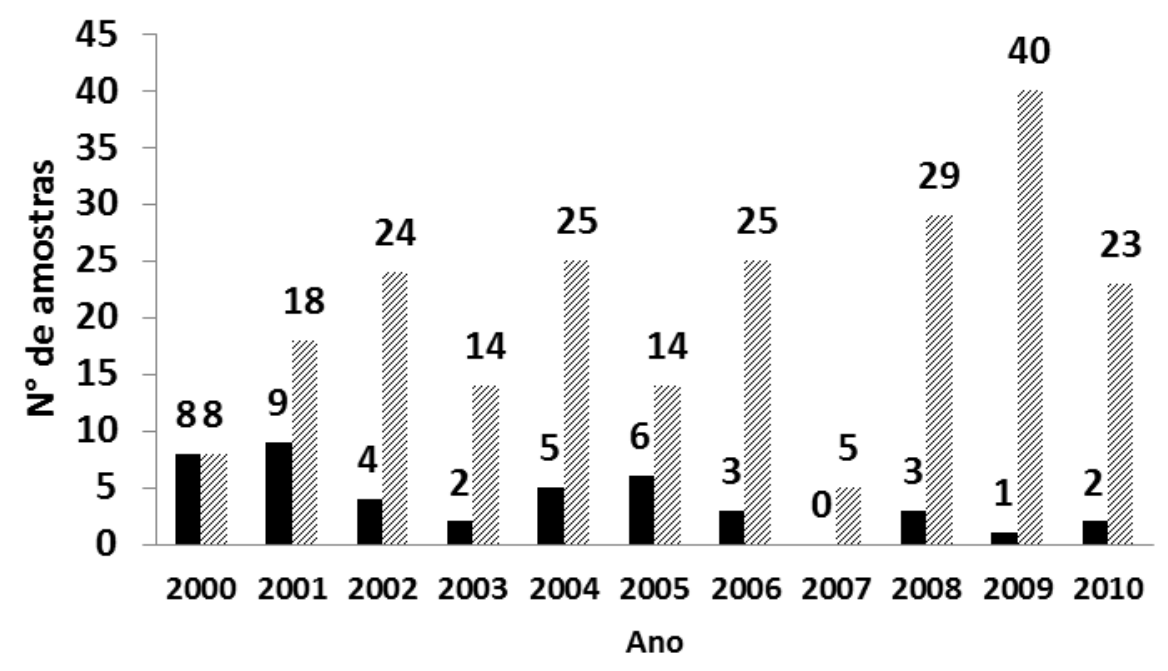

FIGURA 3. Quantidade de amostras positivas e negativas ao vírus da raiva, encaminhados ao Laboratório de Análises e Diagnóstico Veterinário (LABVET) de Goiânia, no período de 2000 a 2010 da região do Alto Araguaia de Goiás. 
No ano de 2000 a 2010 houve uma diminuição de animais infectados, levando em consideração que no ano de 2000 foram encontrados 8 animais infectados, enquanto que em 2010 apenas 2 (Figura 3), sendo os 8 animais no ano de 2000 e os 2 do ano de 2010 trata-se de bovinos. Em relação aos equinos, das 2 amostras pesquisadas no laboratório neste mesmo período, nenhuma foi positiva (Tabela 1 ).

Os morcegos capturados para análise não houve positividade ao vírus (Tabela 1). Todos os morcegos hematófagos capturados são da família Phyllostomidae (Desmodus rotundos), totalizando em 62 machos e 34 fêmeas (Figura 4). Quanto aos morcegos não hematófagos também não houve incidência de positividade em relação ao vírus, os quais todos foram da família Molossidae (20 fêmeas e 6 machos) e 4 espécies que não foram identificadas (Figura 4).

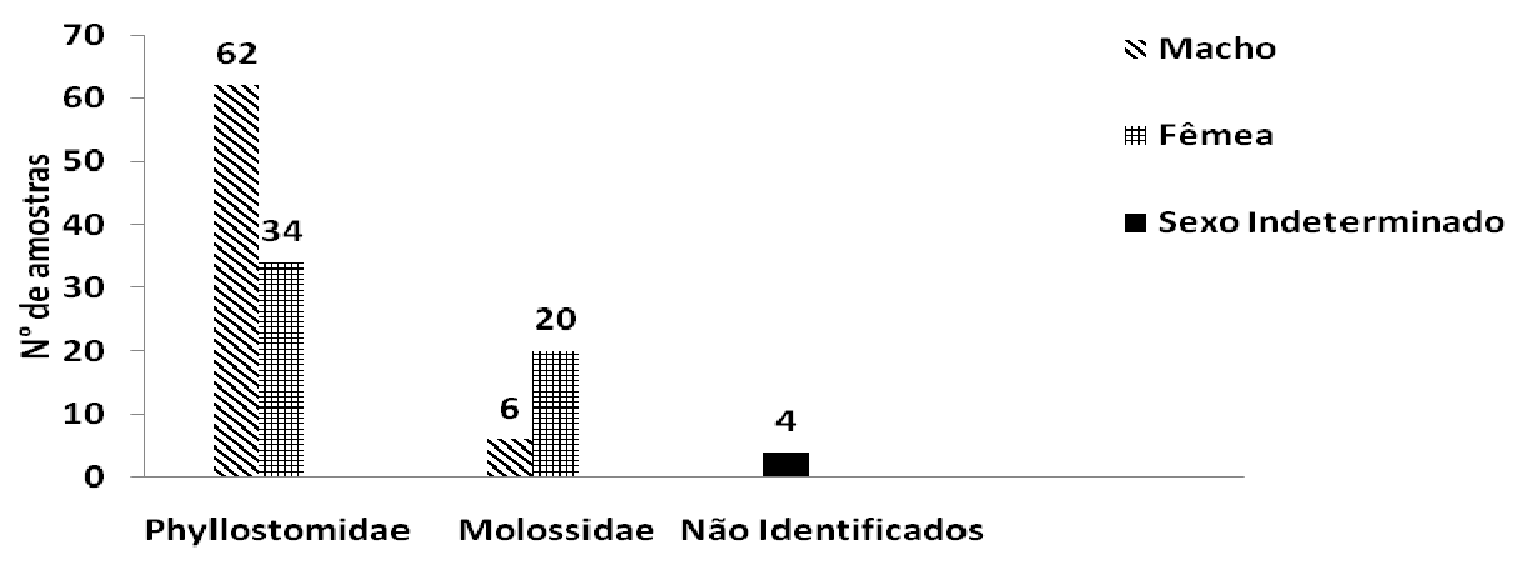

FIGURA 4. Distribuição dos morcegos de acordo com a família e sexo, capturados e examinados no Laboratório de Análises e diagnóstico Veterinário (LABVET) de Goiânia, no período de 2000 a 2010 na região do Alto Araguaia no Estado de Goiás.

Nos municípios da região Sudoeste, foram diagnosticados 68 bovinos positivos e 137 negativos, sendo relatados uma maior incidência no município de Paraúna com 11amostras positivas, seguido por Acreúna e Santo Antonio da Barra com 9 casos (Tabela 2). No ano de 2005 verifica-se uma grande ocorrência animais infectados (31), sendo os bovinos responsáveis por 29, 
SILVA, L.A. e CABRAL, S.R.P. A incidência do vírus rábico transmitido por quirópteros nas regiões do Alto Araguaia e Sudoeste de Goiás. PUBVET, Londrina, V. 6, N. 22, Ed. 209, Art. 1396, 2012.

portanto, os bovinos resultam somente no ano de 2005 em 42,65\% dos casos de infectados no decorrer dos anos de levantamento (Figura 5).

Os equinos apresentaram uma quantidade menor de indivíduos contaminados em comparação aos bovinos, com 8 positivos (Tabela 2). Os municípios de Acréuna e Paraúna apresentaram maior incidência de equinos contaminados, sendo em cada município com 2 casos (Tabela 2). Durante o período foram encaminhados 10 morcegos para análise (Tabela 2), sendo quatro da familia Phyllostomidae (Desmodus rotundos) machos, três fêmeas e um macho da família Molossidae, um macho da família Vespertilionidae e uma espécie não identificada (Figura 6).

TABELA 2. Resultados das amostras positivas (Pos.) e negativas (Neg.) da Região Sudoeste de Goiás para o vírus raiva, pela técnica de imunofluorescência direta e inoculação em camundongos, realizado no Laboratório de Análises e diagnóstico Veterinário (LABVET) de Goiânia em bovinos, equinos, morcegos hematófagos (MH) e morcegos não hematófagos (MNH), no período de 2000 a 2010.

\begin{tabular}{|c|c|c|c|c|c|c|c|c|c|}
\hline \multirow{2}{*}{ Municípios } & \multicolumn{2}{|c|}{ Bovinos } & \multicolumn{2}{|c|}{ Equinos } & \multicolumn{2}{|c|}{$\mathrm{MH}$} & \multicolumn{2}{|c|}{$\mathrm{MNH}$} & \multirow{2}{*}{ Total } \\
\hline & Pos. & Neg. & Pos. & Neg. & Pos. & Neg. & Pos. & Neg. & \\
\hline Acreúna & 9 & 7 & 2 & 2 & 0 & 0 & 0 & 0 & 20 \\
\hline Aurilândia & 4 & 6 & 0 & 3 & 0 & 0 & 0 & 0 & 13 \\
\hline Cachoeira Alta & 0 & 15 & 0 & 0 & 0 & 0 & 0 & 0 & 15 \\
\hline Cachoeira de Goiás & 2 & 2 & 0 & 0 & 0 & 0 & 0 & 0 & 4 \\
\hline Castelândia & 1 & 0 & 0 & 0 & 0 & 0 & 0 & 0 & 1 \\
\hline Firminópolis & 0 & 1 & 0 & 0 & 0 & 0 & 0 & 0 & 1 \\
\hline Gouverlândia & 0 & 1 & 0 & 0 & 0 & 0 & 0 & 0 & 1 \\
\hline Indiara & 8 & 10 & 0 & 3 & 0 & 0 & 0 & 0 & 21 \\
\hline Jandaia & 4 & 6 & 1 & 0 & 0 & 0 & 0 & 1 & 12 \\
\hline Maurilândia & 0 & 3 & 0 & 0 & 0 & 0 & 0 & 0 & 3 \\
\hline Montividiu & 1 & 7 & 0 & 0 & 0 & 0 & 0 & 0 & 8 \\
\hline Palminópolis & 0 & 1 & 0 & 0 & 0 & 0 & 0 & 0 & 1 \\
\hline Paranaiguara & 2 & 1 & 0 & 0 & 0 & 0 & 0 & 0 & 3 \\
\hline Paraúna & 11 & 9 & 2 & 2 & 0 & 0 & 0 & 0 & 24 \\
\hline Quirinópolis & 0 & 19 & 0 & 0 & 0 & 0 & 0 & 2 & 21 \\
\hline Rio Verde & 8 & 16 & 1 & 0 & 0 & 1 & 0 & 1 & 27 \\
\hline Santa Helena de Goiás & 2 & 8 & 0 & 0 & 0 & 0 & 0 & 0 & 10 \\
\hline Santo Antonio da Barra & 9 & 2 & 1 & 0 & 0 & 0 & 0 & 0 & 12 \\
\hline São João da Paraúna & 0 & 3 & 0 & 1 & 0 & 0 & 0 & 0 & 4 \\
\hline São Luis dos Montes Belos & 6 & 15 & 0 & 0 & 0 & 0 & 0 & 1 & 22 \\
\hline São Simão & 0 & 3 & 1 & 0 & 0 & 3 & 0 & 1 & 8 \\
\hline Turvânia & 1 & 1 & 0 & 0 & 0 & 0 & 0 & 0 & 2 \\
\hline Tuverlândia & 0 & 0 & 0 & 0 & 0 & 0 & 0 & 0 & 0 \\
\hline Vicentinópolis & 0 & 1 & 0 & 0 & 0 & 0 & 0 & 0 & 1 \\
\hline Total & 68 & 137 & 8 & 11 & 0 & 4 & 0 & 6 & 234 \\
\hline
\end{tabular}



regiões do Alto Araguaia e Sudoeste de Goiás. PUBVET, Londrina, V. 6, N. 22, Ed. 209, Art. 1396, 2012.

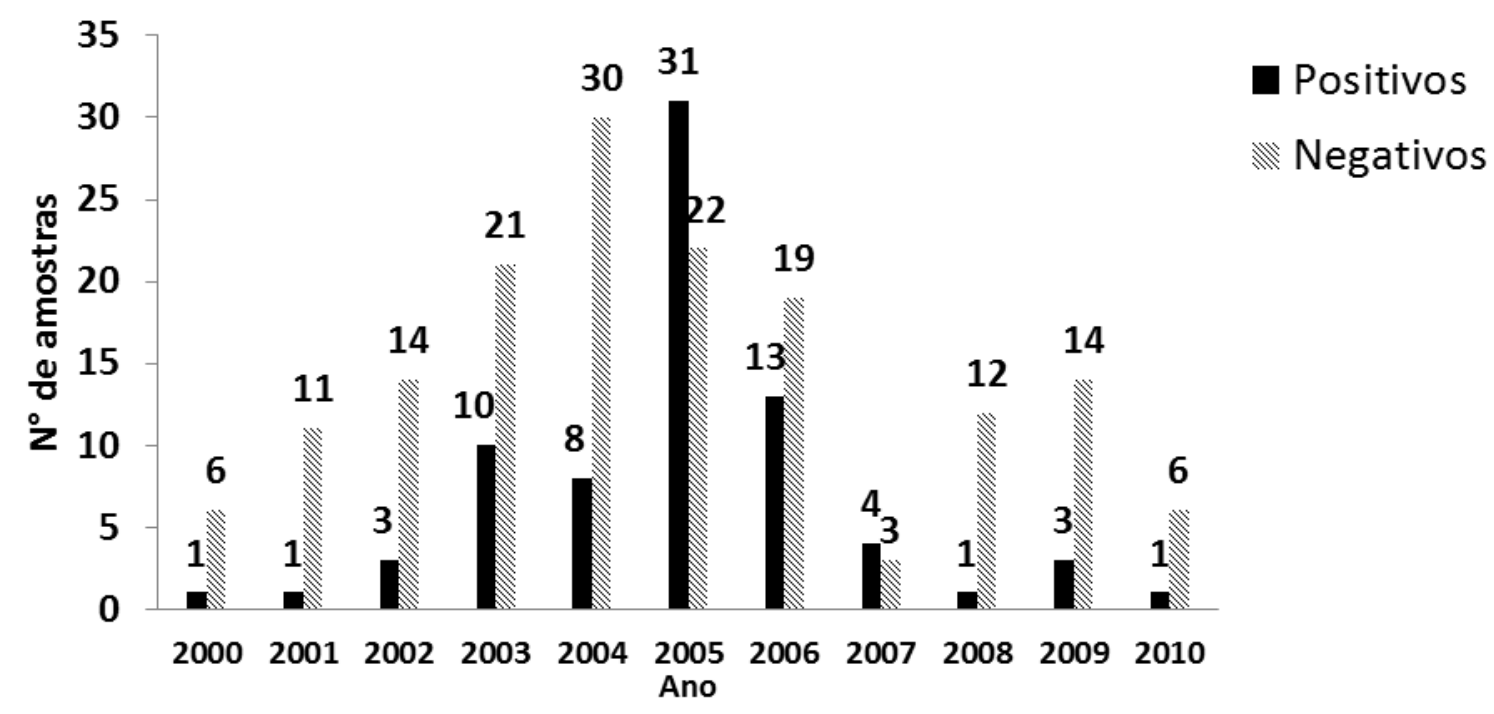

FIGURA 5. Quantidade de amostras positivas e negativas ao vírus da raiva, encaminhados ao Laboratório de Análises e Diagnóstico Veterinário (LABVET) de Goiânia, no período de 2000 a 2010 da região do Sudoeste de Goiás.

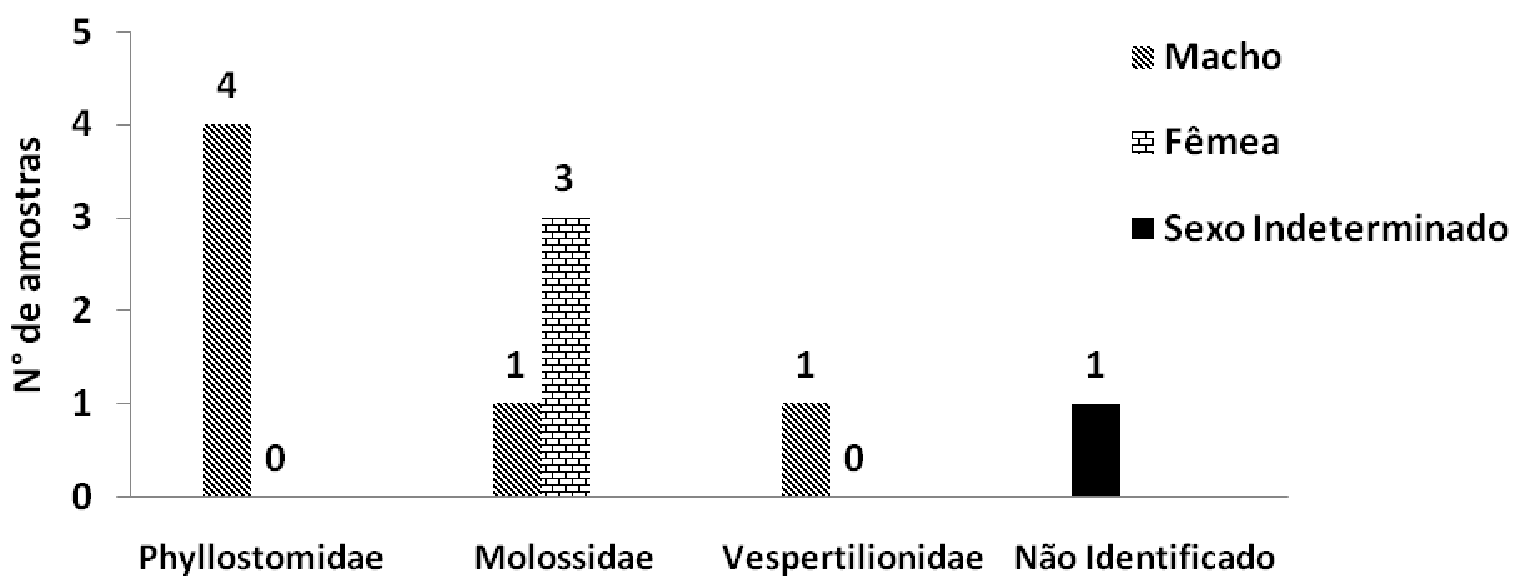

FIGURA 6. Distribuição dos morcegos de acordo com a família e sexo, capturados e examinados no Laboratório de Análises e diagnóstico Veterinário (LABVET) de Goiânia, no período de 2000 a 2010 na região do Sudoeste do Estado de Goiás.

No meio rural as espécies mais acometidas pelo vírus rábico são os bovinos, o que pode ser em decorrência do tamanho populacional. No Estado de Goiás, no período de 1991 a 2001, foram diagnosticados pelo Centro de Diagnósticos e Pesquisa Veterinárias (CDPV) 858 casos positivos de raiva em quirópteros, bovinos e equinos; sendo 753 de bovinos, 38 em equinos e 67 em 
SILVA, L.A. e CABRAL, S.R.P. A incidência do vírus rábico transmitido por quirópteros nas regiões do Alto Araguaia e Sudoeste de Goiás. PUBVET, Londrina, V. 6, N. 22, Ed. 209, Art. 1396, 2012.

quirópteros (SANTOS et al., 2006). A não verificação da presença do vírus em quirópteros no período de 2000 a 2010 nas regiões Sudoeste e do Alto Araguaia, deve-se, provavelmente, ao baixo número de amostras enviadas, porém verifica-se que de 1991 a 2010 os índices de bovinos contaminados continuam sendo preocupantes para a pecuária no Estado de Goiás.

Apesar de não terem sido registrados morcegos contaminados com o vírus rábico, o número de bovinos e equinos indicam sua participação na transmissão do vírus. No Ciclo silvestre da doença, os principais reservatórios do vírus rábico são os quirópteros e primatas, enquanto que no ciclo urbano, são os cães domésticos (PACHECO et al., 2009). Contudo, com o progressivo controle da raiva canina e a redução dos casos em humanos, os morcegos tem se tornado importantes na transmissão do vírus também na zona urbana. Em seus estudos Takaoka e Omata (1998) consideram os morcegos como os segundos transmissores do vírus para os seres humanos. Outro fator preocupante é o aumento das populações de morcegos na zona urbana, devido ao desmatamento (DEUS et al., 2003).

A maioria dos morcegos enviados para análise foram os hematófagos, que são considerados os responsáveis pela transmissão direta do vírus rábico entre os herbívoros. Estes morcegos estão incluídos na família na família Phillostomidae, que é considerada a mais diversificada da região Neotropical, e a subfamília Desmodontinae, que inclui as espécies hematófagas consideradas endêmicas nas Américas (REIS et al., 2007). A espécie Desmodus rotundus é o principal transmissor da raiva na América Latina (RODRIGUES et al., 2007) sendo essa espécie a única da subfamília Desmodontinae relatada no presente trabalho.

Cabe lembrar que a quantidade de bovinos infectados nas regiões de estudo é bastante preocupante, segundo Aiello \& Mays (2001) o morcego Desmodus rotundus representa um dos causadores de maior surto em bovinos e algumas vezes até no homem. Desmodus rotundus apresenta uma ampla distribuição geográfica, sendo encontrado em todo território brasileiro. A 

regiões do Alto Araguaia e Sudoeste de Goiás. PUBVET, Londrina, V. 6, N. 22, Ed. 209, Art. 1396, 2012.

presença do vírus da raiva nesta espécie de morcego é reportada em vários trabalhos com o de Souza et al. (2005) e Scheffer et al. (2007). Além disso, dois outros hematófagos fazem parte da transmissão os Diphylla ecaudata e Diaemus youngi, porém sua participação é irrelevante na disseminação do vírus (BATISTA et al., 2007), estas espécies não têm ocorrência relatada para o estado de Goiás.

Dos morcegos não hematófagos encaminhados para análise constam às famílias Molossidea e Vespertilionidae, onde estes por sua vez, não foram reagentes ao vírus, porém em outros trabalhos verifica-se um crescente número de casos reportados na disseminação do vírus em herbívoros. $\mathrm{Na}$ América Latina mais de 50 espécies já foram relatadas e no Brasil 27 espécies (SILVA et al.,1999). Souza et al. (2005) relatou a presença do vírus no município de Anhembi-SP em 2 insetívoros, Tadarida brasiliensis e Molossus molossus. Scheffer et al. (2007) relata em estudo a ocorrência de amostras positivas de morcegos não hematófagos, incluindo aos gêneros Artibeus, Myotis, Eptesicus, Lasiurus, Nyctinomops, Tadarida (T. brasiliensis), Histiotus, Molossus e Eumops. Segundo Ueida et al. (1995), foram encontrados 4 morcegos insetívoros positivos ao vírus, diagnosticado 2 nas espécies Nyctinomops macrotis, 1 Nyctinomops laticaudatus e 1 Molossus molossus. Albas et al. (2009) relatou em suas análises, amostras positivas em: 1 Myótis nigricans, 11 Artibeus lituratus, 1 Molossus rufus, 1 Artibeus fimbriatus, 1 Artibeus jamaicensis, 1 Molossus, 1 Eptesicus furinalis e 1 Lasiurus ega.

Verifica-se também nos trabalhos de Cunha et al. (2005), Silva et al. (2007), Albas et al. (2010), Carneiro et al. (2009), Deus et al. (2003), Almeida et al. (1994), Santos et al. (2006) e Pacheco et al. (2010) a disseminação da infecção do vírus em morcegos não hematófagos. Os herbívoros são considerados hospedeiros acidentais do vírus da raiva (BRASIL, 2009), porém não se deve desprezar sua participação na manutenção do vírus (SOUZA et al., 2005). 

regiões do Alto Araguaia e Sudoeste de Goiás. PUBVET, Londrina, V. 6, N. 22, Ed. 209, Art. 1396, 2012.

Estudos apontam que a ausência de infecção ao vírus rábico em quirópteros como no presente trabalho, pode significar também que o morcego que desenvolve a doença, deixa seu abrigo com uma freqüência menor, ou caso saia, fica vulnerável aos predadores, e até mesmo chega a morrer em seu próprio abrigo (SOUZA et al., 2005), assim também, verifica-se a ausência de infecção nos estudos de Zortea et al. (2010). Outro fator a ser considerado é o número baixo de amostras enviadas para análise, proveniente das regiões do estudo durante o período, e também o estudo simplificado dos animais capturados que são classificados em hematófagos e não hematófagos e quanto ao sexo. Uieda et al. (1995) considera que a identificação correta da espécie fundamental para o conhecimento da biologia dos animais e que isto tem prejudicado o conhecimento do papel das diferentes espécies de quirópteros na epidemiologia da raiva.

Outro fator preocupante a ser considerado é a atividade continua de vigilância epidemiologia para se ter um maior controle de populações de Desmodus rotundus, esclarecendo com programas informativos aos criadores quando detectarem a presença desses animais em suas propriedades (SCHNEIDER, 1996), mesmo que os índices de positividade ao vírus rábico sejam irrelevantes como no presente trabalho, pois deve se levar em consideração a possível disseminação do vírus em outros animais que servem como reservatório, cabendo ao proprietário alertar imediatamente o Serviço Veterinário Oficial com relação a animais suspeitos de ataques, considerando que a não notificação pode sujeitar o seu rebanho à enfermidade, assim também como em outras espécies de animais da região, incluindo a população humana local (BRASIL, 2005).

Segundo Ministério da Agricultura, Pecuária e Abastecimento - MAPA (BRASIL, 2005) a vacinação compulsória deve ser provisória, portando sendo suspensa assim que a região estiver em níveis satisfatório no controle da raiva, com isso a vacinação é recomendada principalmente para rebanhos de equinos e bovinos com idade a partir de 3 meses de idade. Considerando a importância 
da vacinação, ressalta-se que na América Latina aproximadamente 500 mil animais estão submetidos à doença, levando se em consideração que no ano de 1997 em Minas Gerais, cerca de 4000 cabeças de bovinos foram contaminados pelos vírus da raiva, representando um prejuízo de dois milhões de reais por ano (BARROS et al., 2006). Contudo, uma vez iniciado os sintomas nos animais infectados, deve-se isolar o animal e esperar a sua morte ou sacrificá-lo na fase agônica (BRASIL, 2005).

Vale ressaltar a importância de adotar maior atividade em capturas de morcegos nas regiões do Alto Araguaia e Sudoeste de Goiás, pois se deve considerar que há grande predominância de bovinos infectados nessas regiões, verificando assim, uma deficiência no controle de quirópteros, permanecendo de forma relevante a quantidade de animais infectados.

\section{CONCLUSÃO}

Todas as amostras de morcegos mostraram-se negativas ao vírus rábico, porém verifica-se um grande número de bovinos infectados nas regiões de estudo, além disso, a região Sudoeste realizou um menor encaminhamento de amostras para análise e uma maior quantidade de animais infectados com o vírus da raiva.

Os resultados encontrados reforçam a necessidade que ocorra uma intensificação no sentido de encaminhar um maior número de amostras para análise laboratorial, pelos órgãos responsáveis. Sugere-se ainda, um estudo completo sobre os aspectos biológicos dos quirópteros encaminhados para análise, o que contribuirá para o conhecimento destes animais na epidemiologia da raiva. 


\section{REFERÊNCIAS}

ACHA, P.N.; SYFRES, B. Zoonoses and Communicable Disease Commom to Man and Animals. 3. Ed. Washington: Rev. Panam. Salud Públ., v.2, 425 p., 2003.

AIELLO, S.E.; MAYS, A. Manual Merck de Veterinária. 2. ed. São Paulo: Roca, 797 p., 2001.

ALBAS, A.; SOUZA, E.A.N.; LOURENÇO, R.A.; FAVORETTO, S.R.; SODRÉ, M.M. Perfil Antigênico do Vírus da Raiva Isolado de Diferentes Espécies de Morcegos Não Hematófagos da Região de Presidente Prudente, Estado de São Paulo. Rev. Soc. Bras. Med. Trop., v. 42, n.1, p. 15-17, 2009.

ALBAS, A.; SOUZA, E.A.N.; PICOLO, M.R.; FAVORETTO, S.R.; GAMA, A.R.; SODRÉ, M.M. Os Morcegos e a Raiva na Região Oeste do Estado de São Paulo. Rev. Soc. Bras. Med. Trop., 2010.

ALMEIDA, M.F.; AGUIAR, E.A.C.; MARTORELLI, L.F.A.; SILVA, M.M.S. Diagnóstico laboratorial de raiva em quirópteros realizado em área metropolitana na região sudeste do Brasil. Rev. Saúde Públ., v. 28, n. 5, p. 341-344, 1994.

BARROS, C.S.L.; DRIEMEIER, D.; DUTRA, I.S.; LEMOS, R.A.A. Doenças do Sistema Nervoso de Bovinos no Brasil. São Paulo: Rev. Alea., p. 21-28, 2006.

BATISTA, H.B.C.R.; FRANCO, A.C.; ROEHE, P.M. Raiva: Uma Breve Revisão. Porto Alegre: Acta Sci. Vet., v. 35, n. 2, p. 125-144, 2007.

BRASIL. Controle da Raiva dos Herbívoros: Manual Técnico 2005. Brasília: MPA/DAS/DSA-Ministério da Agricultura, Pecuária e Abastecimento, 104 p., 2005.Disponível:http://www.fundepecpr.org.br/conteudo/principal/sanid bovidea/encefalopati as/raiva/pdf/MANUAL TECNICO 2005.pdf. Acessado em: 24 Nov. 2011.

BRASIL. Controle da Raiva dos Herbívoros: Manual Técnico 2009. Brasília: MAPA/ACSMinistério da Agricultura, Pecuária e Abastecimento, 124 p., 2009. Disponível: http://www.agricultura.gov.br/arq editor/file/Aniamal/programa\%20nacional\%20dos\%20herbi voros/manual\%20tecnico\%20para\%20controle\%20da\%20raiva.pdf. Acessado em: 27 Nov. 2011.

BRASIL. Situação Epidemiológica Das Zoonoses de Interesse para a Saúde Pública. Brasilia/DF: Secretária de Vigilância em Saúde, Brasília, n. 2, 2010. Disponível em: http://portal.saude.gov.br/portal/arquivos/pdf/boletim eletronico 02 ano10.pdf. Acessado em: 05 Nov. 2011.

CARNEIRO, N.F.F.; CALDEIRA, A.P.; ANTUNES, L.A.; CARNEIRO, V.F.; CARNEIRO, G.F. Raiva em Morcegos Artibeus lituratus em Montes Claros, Estado de Minas Gerais. Rev. Soc. Bras. Med. Trop., v. 42, n. 4, p. 449-451, 2009.

CUNHA, E.M.S.; QUEIROZ DA SILVA, L.H.; LARA, M.C.C.S.H.; NASSAR, A.F.C.; ALBAS, A.; SODRE, M.M.; PEDRO, W.A. Bat Rabies in the North-Northwestern Regions of São Paulo State - Brazil, 1997-2002. Rev. Saúde Públ., v.40, n. 6, p. 1082-1086, 2006.

CUNHA, E.M.S.; LARA, M.C.C.S.H.; NASSAR, A.F.C.; SODRÉ, M.M.; AMARAL, L.F. Isolamento do Vírus da Raiva em Artibeus fimbriatus no Estado de São Paulo. Rev. Saúde Públ., v. 39, n. 4, p. 683-684, 2005. 
DEUS, G.T.; BECER, M.; NAVARRO, I.T. Diagnóstico da Raiva em Morcegos Não Hematófagos na Cidade de Campo Grande, Mato Grosso do Sul, Centro Oeste do Brasil: Descrição de Casos. Londrina: Semina Ciênc. Agrar., v. 24, n. 1, p. 177-176, 2003.

KAPLAN, M.M.; KOPROWSKI, H.; MESLIN, F-X. Laboratory Techniques in Rabies. 4th ed. Geneva: World Health Organization, p. 476, 1996.

KOTAIT, I.; CARRIERI, M.L.; TAKAOKA, N.Y. Raiva - Aspectos Gerais e Clínica. Manuais 8. São Paulo: Inst. Pasteur, p. 49, 2009.

LAZARINI, S.R.F. Antigenic and Genetic Study of Rabies Vírus Isolated from Humans in Brazil. In: SEMINÁRIO INTERNACIONAL DE RAIVA, 2003, São Paulo. Resumos... São Paulo: Inst. Pasteur, p.16-17, 2003.

LEMOS, R.A.A.; CAVALLÉRO, J.C.M. (Ed.). Manual de Procedimentos para Diagnóstico Histológico Diferencial da Encefalopatia Espongiforme dos Bovinos (BSE). São Paulo: Lemos, p. 31-48, 2001.

Organização Mundial da Saúde. International Travel and Health. Geneva: OMS, 84 p., 2005.

PACHECO, S.M.; CALDAS, E.P.; ROSA, J.C.A.; ROSA, D.P.; BATISTA, H.; FERREIRA, J.C.; PREDEBOM, J.; ROEHE, P.M. Registro de Artibeus lituratus (Olfers, 1818) (Chiroptera: Phyllostomidae) Positivo para o Vírus Rábico no Estado do Rio Grande do Sul, Brasil. Porto Alegre: Rev. Bras. Bioci., v. 8, n. 1, p. 61-63, 2010.

REIS, N.R.; PERACCHI, A.L.; PEDRO, W.A.; LIMA, I.P. Mamiferos do Brasil. Londrina, 437 p., 2006.

REIS, N.R.; PERACCHI, A.L.; PEDRO, W.A.; LIMA, I.P. Mamiferos do Brasil. Londrina, 253 p., 2007.

RODRIGUEZ, L.L.; ROEHE, P.M.; BATISTA H. \& KURAT G. 2007. Rhabdoviridae. (Ed). Virologia veterinária, p. 691-718, 2007.

SANTOS, M.F.C.S; RESENDE, R.M; SOBRINHO, R.N; VIEIRA, S. Diagnóstico Laboratorial da Raiva no Estado de Goiás no Período de 1976 a 2001. Ciênc. Anim. Bras. de Goiania, v. 7, n. 1, p. 77-83, 2006

SCHEFFER, K.C.; CARRIERI, M.L.; ALBAS, A.; SANTOS, H.C.P.; KOTAIT, I.; ITO, F.H. Vírus da Raiva em Quirópteros Naturalmente Infectados no Estado de São Paulo, Brasil. Rev. Saúde Públ., v. 41, n. 3, p. 389-95, 2007.

SCHNEIDER, M. C., ALMEIDA, G. A., SOUZA, L. M., MORARES, N. B., DIAZ, R. C. Controle da Raiva no Brasil, de 1980 a 1990. Rev. Saúde Públ., v.30, p.196-203, 1996.

SCHNEIDER, M.C.; BELOTTO, A.; CORREA, E.; TAMOYO, H.; LEANES, L.F. Raiva Canina: Área Controlada e Não Controlada. In: Seminário Internacional de Raiva. São Paulo: Pasteur; p.24-25, 2003.

SCHNEIDER, M.C.; ROMIJN, P.C.; UIEDA, W.; TAMAYO, H.; SILVA, D.F. da.; BELOTTO, A.; SILVA, J.B.; LEANES, F.F. Rabies Transmitted by Vampire Bats to Humans: na Emerging Zoonotic Disease in Latin American? Rev. Panam. Salud Públ., v. 25, n. 3, p. 260-269, 2009. 
SILVA, A.C.R.; CAPORALE, G.M.M.; GONÇALVES, C.A.; TARGUETA, M.C.; COMIN, F.; ZANETTI, C.R.; KOTAIT, I. Antibodiy Response in Cattle After Vaccination With Inactivated and Attenuated Rabies Vaccines. São Paulo: Rev. Inst. Med. Trop., v. 42, n. 2, p. 95-98, 2000.

SILVA, A.R.P. Pólo Regional ou Cluster: 0 Caso do Município de Rio Verde, Goiás Brasil. Caminhos de Geografia, v. 5, n. 13, p. 41-55, 2004.

SILVA, L. H. Q.; CUNHA, E.M.S.; PEDRO, W.A.; CARDOSO, T.C.; SOUZA, M.M.C.; FERRARI, C.I.L. Isolamento do Vírus Rábico em Molossus ater no Estado de São Paulo. Rev. Saúde Públ., v. 33, n. 6, 1999.

SILVA, M.V.; XAVIER, S.M.; MOREIRA, W.C.; SANTOS, B.C.P.; ESBÉRARD, C.E.L. Vírus Rábico em Morcego Nyctinomops laticaudatus na Cidade do Rio de Janeiro, RJ: Isolamento, Titulação e Epidemiologia. Rev. Soc. Bras. Med. Trop., v. 40, n. 4, p. 479481, 2007.

SILVA, R.C.; LANGONI, H.; Epidemiologia da Raiva em Quirópteros e os Avanços em Biologia Molecular. Vet. e Zoot., v. 18, n. 1, p. 19- 37, 2011.

SIMMONS, N.B. Mammal Species of the World: a Taxonomicand Geographic Reference, 3th ed. (D.E. Wilson and D.M Reeder, eds.). Johns Hopkins University Press. Order Chiroptera, v.1, p. 312-529, 2005.

SOUZA, L.C.; LANGONI, H.; SILVA, R.C.; LUCHEIS, S.B. Vigilancia Epidemiologica da Raiva na Região de Botucatu-SP: Importancia dos Quiropteros na Manutenção dos Virus na Natureza. Jaboticabal, SP: ARS Veterinária, v. 21, n. 1, p. 62-68, 2005.

TAKAOKA, N.Y.; OMATA, T.M. Raiva Humana Transmitida por Morcegos no Estado de São Paulo, Brasil. In: Seminário Internacional Morcegos como Transmissores da Raiva, 1998, São Paulo. Programa e resumos... São Paulo: Parlamento Latino Americano, 2001.

UIEDA, W.; HARMANI, N.M.S.; SILVA, M.M.S. Raiva em Morcegos Insetívoros (Molossidae) do Sudeste do Brasil. Rev. Saúde Públ., v. 29, n. 5, p. 393-397, 1995.

ZORTEA, M.; MELO, F.R.; CARVALHO, J.C.; ROCHA, Z.D. Morcegos da Bacia do Rio Corumbá, Goiás. Chiroptera Neotropical, v.16, n. 1, p. 610-616, 2011.

WARRELL, M.J.; WARRELL, D.A.M. Rabies and Other lyssavirus diseases. Lancet, v. 363, p. 959-969, 2004.

WILSON, D.E.; REEDER, D.M. (Eds). Mammal Species of the World: a Taxonomic and Geographic Reference. 3.ed. Baltimore: Johns Hopkins University Press, v. 1, p. 2181, 2005. 